\title{
Ação empresarial na escola: os impactos no trabalho docente e as suas resistências associadas à cultura escolar
}

\section{Business action at school: the impacts on teaching work and its resistance associated with school culture}

\author{
DOI: $10.46814 / \operatorname{lajdv3n1-029}$
}

Recebimento dos originais: 30/10/2020

Aceitação para publicação: 23/12/2020

\author{
Cristiane de Almeida Jardim \\ Mestranda em Ciências Sociais na Universidade Federal de Santa Maria (UFSM) \\ Instituição de atuação atual: UFSM \\ Endereço: Centro de Ciências Sociais e Humanas, Departamento de Ciências Sociais, \\ Universidade Federal de Santa Maria (UFSM) - Campus de Santa Maria. Avenida Roraima 1000 - \\ Cidade Universitária, Bairro Camobi, 97105-900, Santa Maria, Brasil. \\ E-mail: cris-jardim2011@ hotmail.com
}

\section{RESUMO}

Este artigo analisa a introdução da lógica empresarial na gestão da escola pública estadual entre os anos de 2015-2020. Para tanto, apresenta projetos de dois governos gaúchos que aproximam a escola de ações empresariais. E demonstra como as parcerias público-privado na escola fortalecem a formação que beneficia a empresa. Na cidade de Santa Maria/RS, realizaram-se entrevistas com profissionais da educação, bem como análise documental. Entende-se que há ações que caracterizam um "quasemercado" na escola. Há uma intensificação do trabalho docente e, em contrapartida, ampliam-se as resistências dos professores associado à defesa de uma cultura da escola baseada em uma lógica de autonomia docente e discente. Este artigo busca contribuir com pesquisas sobre como ações empresariais, na e para a escola, têm intensificado uma formação para o mercado de trabalho, bem como as formas de conflitos associadas a essas diretrizes.

Palavras-chave: ação empresarial, trabalho docente, cultura da escola, formação escolar.

\begin{abstract}
This article analyzes the introduction of business management mechanisms in the management of the state public school between the years 2015-2020. To this end, it presents projects by two gaucho governments that bring the school closer to business actions. And it demonstrates how public-private partnerships at school strengthen the training that benefits the company. In the city of Santa Maria/RS, interviews with education professionals were carried out, as well as documentary analysis. It is understood that there are actions that characterize a "quasi-market" at school. There is an intensification of the teaching work and, on the other hand, the resistance of the teachers is associated with the defense of a school culture based on a logic of teaching and student autonomy. It seeks to contribute to researches on how business actions in and for the school have intensified school education for the job market, as well as the forms of conflicts associated with these guidelines.
\end{abstract}

Keywords: business action, teaching work, school culture, school training. 


\section{INTRODUÇÃO}

O propósito do artigo é analisar, junto à três escolas públicas estaduais com ensino médio de diferentes regiões da cidade de Santa Maria/RS, a introdução da lógica empresarial na gestão da escola no período que corresponde aos anos de 2015-2020. Busca-se analisar aspectos da cultura da escola que permitam observar em que medida há resistências dos docentes no tocante à adesão a lógica empresarial. Neste artigo, a cultura da escola é entendida como o conjunto de valores, representações e crenças presentes nas três escolas públicas estaduais de ensino médio de Santa Maria/RS selecionadas para esta pesquisa. Busca-se mostrar a resistência da cultura da escola (presente em cada estabelecimento de ensino) à introdução de lógicas mercantis no seu modo de funcionamento. Sendo assim, os interlocutores no exercício da sua atividade procuram contrapor as pressões das lógicas focadas na eficácia escolar e ajustamento, articulando com formas de agir orientados por outros referenciais normativos (o que poderemos observar, por exemplo, nos projetos desenvolvidos pela escola).

Segundo Nóvoa (1995), as escolas mesmo integradas em contextos sócio-culturais mais amplos, também produzem sua cultura interna que reflete os valores, representações e crenças de seus membros. Portanto, a cultura da escola se refere aos modos particulares de interagir, de trabalhar, de agir e de pensar que se consolidam nas práticas cotidianas e expressam o "modo de ser particular" da escola (Nóvoa, 1995). Em relação a resistência dos professores associada a cultura da escola, Nóvoa (1995) mostra que os elementos culturais, ideológicos, as crenças e as expectativas, vinculadas aos atores da escola podem expressar resistências aos processos que nela se desenvolvem.

Desse modo, a pluralidade dos referenciais de caráter político e moral identificáveis no discurso dos professores não estão sendo cristalizados, mas sim, o desafio é mostrar a resistência da cultura da escola, do campo da pesquisa, frente as últimas mudanças para educação entre os anos de 2015-2020.

O conceito de gestão da escola carrega uma singularidade associada à preocupação com o aprendizado do aluno (Paro, 1998). Nesse particular, a pesquisa indicará os conflitos que envolvem os descontentamentos dos professores em momentos de tensões entre a categoria e a gerência em razão das ações da empresa que, em vista da singularidade do papel da escola, são antagônicas à natureza da gestão da escola. Por isso, se observa, que na cultura da escola é possível identificar resistência à introdução da lógica mercantil no seu modo de funcionamento.

O governo do estado do Rio Grande do Sul (RS) tem estimulado uma formação escolar que contempla demandas do mercado de trabalho. Tal pode ser vista no plano dos projetos do governo para educação. Entre os projetos, destaca-se o chamado “Escola Melhor: sociedade melhor", da gestão do ex-governador José Ivo Sartori (MDB) (2015-2018), e o intitulado “Jovem RS conectado no futuro", da administração do atual governador Eduardo Leite (PSDB) (2019-2020). 
A parceria com o Sistema S[1] - que é como se define o conjunto de organizações das entidades corporativas voltadas para o treinamento profissional, assistência social, consultoria, pesquisa e assistência técnica - também beneficia uma formação pensada para o mercado de trabalho. Como exemplo, abordar-se-á a parceria da escola com o Serviço Nacional de Aprendizagem Industrial (SENAI-RS).

Observou-se uma intensificação do trabalho docente. Para melhor compreensão, mostrar-se-á como esse ponto se desenvolve tendo como base um modelo de sociedade articulada pelo projeto neoliberal que inicia com a eleição do presidente da república Fernando Collor de Melo em 1989.

\section{APRESENTAÇÃO METODOLÓGICA}

Esta pesquisa iniciou-se junto à três escolas públicas estaduais de ensino médio da cidade de Santa Maria/RS tendo por propósito analisar a introdução de mecanismos da gestão empresarial na gestão da escola entre os anos de 2015-2020. Dessa forma, foram entrevistados três professores, quatro coordenadores pedagógicos, uma diretora e uma vice-diretora. Vale ressaltar que o artigo tem uma natureza ainda eminentemente exploratória de entrevistas.

Portanto, entre as vinte e quatro escolas públicas estaduais de ensino médio da cidade de Santa Maria/RS foi selecionado três escolas para a amostra. Cada uma dessas escolas está situada em uma região da cidade, o que permitiu mostrar mais da realidade estudada. Ademais, as entrevistas foram realizadas no período que corresponde aos anos de 2018-2020.

Também, foi realizada análise documental, tendo como fonte os escritos da SEDUC. Isso se deve ao fato de que se observou que esses documentos servem para institucionalizar, nas escolas, os projetos dos governos do estado, estreitando uma relação entre empresa-escola no que se refere às ações de responsabilidade social e empresarial. Outra fonte documental utilizada são os Projetos Políticos Pedagógicos (PPP)[2] no intuito de identificar em que medida a cultura da escola descrita nesses documentos é experienciada na escola. Portanto, a análise documental dos PPP é uma forma de verificar se o conjunto de valores, representações e crenças que constituem a cultura da escola, e que estão apresentados nesse documento, são concretizados na escola.

\section{O ESPÍRITO DA EMPRESA NA ESCOLA}

Para compreendermos como o discurso da responsabilidade social empresarial é justificado no âmbito da escola, são destacados dois projetos pensados para a educação do estado do RS: o primeiro, chamado "Escola Melhor: sociedade melhor”, da gestão do ex-governador José Ivo Sartori (MDB); e o segundo, intitulado "Jovem RS conectado no futuro", da administração do atual governador Eduardo Leite (PSDB). 
Sartori (MDB) através do projeto "Escola Melhor: sociedade melhor”, defendeu a aproximação entre o serviço público e a administração privada. Assim, regularizou parcerias de escolas estaduais com pessoas físicas e jurídicas, para, com isso, essas poderem realizar reformas, ampliações, instalações de redes wi-fi e doações às escolas. Em troca, além de ser reduzida a responsabilidade do governo estadual com a manutenção das instituições escolares, as empresas puderam realizar publicidade dentro das escolas (Estormovski, 2017).

Essas publicidades podem ser de suas marcas, como, por exemplo, de suas pinturas, materiais de instalações, serviços de internet e materiais didáticos. São publicidades dos mais variados serviços que diferentes empresas podem oferecer à escola. Desse modo, segundo a diretora N.A.[3], da escola L.M.[4], as instituições privadas procuram a escola para "vendas veladas de publicidade dentro da escola que geralmente são apresentadas como produtos que a escola precisa" (N.A., entrevista, 2020). Com isso, ocorre, segundo a vice-diretora A.P., da escola R.A., uma busca por novos consumidores, sendo esses os jovens estudantes. Segundo o coordenador pedagógico E.H., da escola L.M.:

O que mobiliza estas instituições privadas é buscar freguesia, é buscar divulgar seus produtos para que as pessoas procurem o produto deles, mas é buscar propaganda, contato com os alunos, para que estes alunos virem consumidores (EH., entrevista, 2020).

A diretora N.A., da escola L.M., esclarece que a SEDUC disponibiliza um modelo padrão de placa, ou pintura em muro, o que as escolas poderão utilizar para divulgar os nomes e/ou logomarcas das empresas parceiras; enquanto a empresa é quem custeia esse material. Além da placa ou pintura, qualquer outro meio de publicidade e marketing disponível pela empresa poderá ser divulgado na escola, tendo a autorização da mesma e concordância da SEDUC. Isso representa uma troca de benefício entre escolas e empresas.

Segundo Estormovski (2017), tais trocas implementa um "quase-mercado" nas escolas estaduais, tendo em vista estas trocas realizarem por meio de uma venda, mesmo que velada, de publicidade dentro das instituições escolares. Abre-se o caminho para o consumo e a competição empresarial dentro dos ambientes escolares, interferindo nos valores da comunidade escolar (Estormovski, 2017).

Essas ações que caracterizam um "quase-mercado" na escola são justificadas tendo como base que muitas das escolas carecem de materiais que, através de empresas, chegam até ao seu espaço. Segundo o coordenador pedagógico E.H., um exemplo disso é que, para a escola L.M., uma entidade ofereceu um projeto com internet de qualidade. A instituição privada, a partir desse suporte tecnológico, conseguiu ganhar espaço e conquistar a adesão da escola para a implementação da sua rede wi-fi. 
No ano de 2017, o secretário da educação do governo Sartori (MDB), Ronald Krummenauer, defendeu como primeira meta do governo para a educação a necessidade de o estado buscar parceria com outros setores da sociedade, como com o Sistema S, para o financiamento da educação (Witter, 2017).

Segundo a vice-diretora A.P., a escola R.A. foi uma das escolas a fazer parceria com uma das entidades do Sistema S, intitulada Serviço Nacional de Aprendizagem Industrial (SENAI-RS). Nas escolas, o SENAI oferece cursos profissionalizantes e técnicos e estágios remunerados aos alunos. Conforme a vice-diretora A.P., a escola R.A. entende a divulgação dos cursos no espaço da instituição e a parceria com as entidades como sendo um auxílio para o aluno continuar estudando. Ou seja, segundo a vice-diretora A.P., a comunidade da escola R.A.:

Atende uma parcela de alunos num quadro de vulnerabilidade social, desse modo, a escola entende que as empresas podem representar uma oportunidade para o aluno se manter financeiramente e estudando, nesse sentido, até pode se pensar (A.P., entrevista, 2020).

Segundo o coordenador pedagógico E.H., da escola L.M., "ofertas de cursos profissionalizantes e estágios na escola, como os do SENAI, seguem a mesma lógica de programas do governo estadual para educação que tem por objetivo implantar na escola a preparação técnica para o trabalho" (E.H., entrevista, 2020). Temos no atual governo do estado, na gestão do governador Eduardo Leite (PSDB), o programa "Jovem RS Conectado no Futuro"[5]. O projeto une esforços coletivos de entidades públicas e privadas em prol da aplicação de uma política de governo para educação. Nesse projeto, as escolas deverão criar práticas empreendedoras, desenvolver a criatividade dos alunos, oportunizar um espaço de desenvolvimento de competências e habilidades que podem servir para diferentes funções que o estudante venha a desempenhar futuramente no mercado de trabalho.

É um trabalho de convencimento do programa “Jovem RS Conectado no Futuro" que se infiltra em diferentes instituições, públicas e privadas, apresentando oportunidades, como, por exemplo, de desenvolvimento econômico e social, via capacitação empreendedora dos jovens para suas cidades. Ou seja, conforme a SEDUC, o programa "Jovem RS Conectado no Futuro", de forma estratégica, define as ações de gestão pedagógica e de planejamento da pasta tendo como proposta valorizar, apoiar e dar visibilidade e estímulo ao crescimento e ao protagonismo juvenil (Scarton, 2019).

A meta do referido projeto para 2020 é atingir mais de $40 \%$ das escolas com selos que irão certificá-las de Escolas Criativas e, até 2022, 100\% das escolas devem estar certificadas (Scarton, 2019). Segundo o secretário da Educação, Faisal Karam, o projeto serve como forma de motivação, procurando contribuir para que os jovens estudantes se mantenham em ambiente escolar. $\mathrm{O}$ governador do estado, Eduardo Leite (PSDB), defende que: 
É fundamental que as escolas contribuam para que os alunos estejam mais adaptados às exigências do mundo atual. A educação tem que estar sintonizada com os novos tempos, que exigem muito mais que o conhecimento formal. Demandam o despertar para habilidades e competências que são requisitados nesse cenário de uma nova economia e que exige criatividade, empreendedorismo e inovação (Scarton, 2019).

O empreendedorismo no Brasil, segundo o relatório do Entrepreneurship Monitor (GEM), de 2018, mostra uma oportunidade para enfrentar barreiras de investimento e de crise econômica (Instituto Brasileiro da Qualidade e Produtividade [IBQP], 2018). Destaca que o incentivo a práticas empreendedoras no ensino médio são um fator importante para encorajar o empreendedorismo jovem eficaz.

O relatório do GEM defende a oferta de estágios para os jovens aprenderem sobre o empreendedorismo; a reforma de leis para tornar mais fácil a abertura de novos negócios; a criação de uma rede de mentoria que conecte jovens e empreendedores de sucesso; e a formação de incubadoras e aceleradoras mais acessíveis para empreendedores em potencial (IBQP, 2018). Ressalta que “enquanto um ambiente global de transformação apresenta desafios de várias naturezas e escalas, está claro que também apresenta oportunidades - em particular, para empreendedores inovadores e dinâmicos" (IBQP, 2018).

Segundo a professora M.A., da escola M.F., os princípios da gestão empresarial comportam um caráter formativo aos alunos. A filosofia dessa formação pretende interiorizar, nos estudantes, uma visão de que podem criar, inventar e serem a arte de si enquanto produzem e contribuem para o pregresso individual e coletivo. Motivados, então, não apenas os que empreenderão no futuro, mas todos concebem a noção de serem autogestores em qualquer cargo que venham conquistar no mercado de trabalho. Segundo a professora M.A., entre os alunos há exceções que podem abrir o próprio negócio, porém, para todos os valores do empreendedorismo podem servir e em qualquer cargo no mercado de trabalho.

Nesse sentido, as noções de educação apresentadas nos governos Sartori (MDB) e Eduardo Leite (PSDB) concebem o chão da escola enquanto um espaço para desenvolver práticas empreendedoras, apontando benefícios para a educação junto com o desenvolvimento econômico e social. 


\section{A CULTURA DA ESCOLA E SUAS RESISTÊNCIAS: DESCONTENTAMENTO DOS PROFESSORES COM AS IMPOSIÇÕES DO ESTADO PARA A EDUCAÇÃO}

A partir do campo estudado, observa-se que a cultura da escola define as relações construídas na escola. Desse modo, a escola expressa, no plano de sua cultura, como observado ao longo da pesquisa, as suas atividades específicas, bem como as posições políticas docentes e um modelo de educação. Em relação a um currículo correspondente à cultura da escola, a escola L.M. defende que seja:

Estruturado de forma a contemplar o ser humano na sua integralidade, sendo necessária uma educação que proporcione o desenvolvimento intelectual, social e cultural, onde o sujeito passe a aprender a pensar, comunicar-se, pesquisar, raciocinar de forma lógica, fazer sínteses e elaborações teóricas, enfim, tornar-se autônomo e independente na construção do seu conhecimento (Projeto Político Pedagógico [PPP], 2018).

Nesse contexto, a escola L.M. apresenta a preocupação de romper com a reprodução de modelos educacionais vigentes. Desse modo, a escola deve "considerar o momento em que vivemos. Momento este, que exige capacidade de provocar rupturas com a reprodução social e voltar-se para a transformação das estruturas" (PPP, escola L.M., 2018). No projeto intitulado Show de talentos, por exemplo, ocorre a preparação para uma cidadania ativa e formação de um aluno crítico, pois esse projeto educativo carrega na bagagem a necessidade de mostrar ao aluno que deve lutar pelos seus direitos. Nas palavras da diretora N.A. da escola L.M.:

Este projeto significa o compromisso político de mostrar ao aluno que se deve lutar para viver um mundo melhor. Deve lutar para viver o seu talento independentemente da cor da sua pele, religião, orientação sexual. Pois devemos reivindicar os nossos direitos ocupando os diferentes espaços e diversificando a realidade (N.A., entrevista, 2020).

Com o projeto "Show de Talentos", também procura-se desenvolver a performance, a comunicação e a autonomia dos estudantes. Trata-se de uma ideia que não envolve aspectos da profissionalização. O trabalho do professor, nesse sentido, pode ser entendido em resposta e como contraproposta a atividades do mundo empresarial realizadas dentro da escola.

Identifica-se elementos que fazem parte da tradição escolar e são mais resistentes às mudanças que correspondem às perspectivas empresariais. Por exemplo, a escola R.A. incorpora, no conteúdo do currículo, uma educação ampla. Isso significa que a instituição escolar organiza atividades para além da clássica sala de aula. A escola R.A incentiva o uso da horta, o consumo sustentável e o consumo de produtos orgânicos. "Os alunos fazem horta, trabalhamos muito a questão ambiental, o cuidado com o lixo, descarte e reciclagem. Trabalhamos com essas atividades diferenciadas, fora da sala de aula" (A.P., entrevista, 2020). 
Analisando as propostas de entidades empresariais, na escola, observou-se suas relações com um modelo de educação beneficiador do mercado. Como exemplo, está a aproximação entre as propostas do SENAI, citadas na primeira parte deste artigo, com o modelo de educação para as competências e habilidades. Esse modelo de educação, sucintamente, significa estar preparando o aluno para uma função no mercado de trabalho. Portanto, a formação para as competências e habilidades, segundo o coordenador pedagógico E.H., da escola L.M., contribui com o fortalecimento do Sistema S - entidades que, conforme o coordenador pedagógico E.H., não apresentam preocupação em criar condições para a autonomia do sujeito, mas sim cumprem a lógica da preparação técnica para o mercado de trabalho. Desse modo, segundo o coordenador pedagógico E.H.:

há um fortalecimento da educação para o trabalho na escola com a formação para as competências e habilidades. Essa formação ajuda ampliar o caminho para o ensino privado, como Sistema $\mathrm{S}$, estar dentro da escola pública. Essa educação não é a que nos comtempla, fortalecimento de uma educação para o trabalho e fragilidade de uma educação para a autonomia do sujeito (E.H., entrevista, 2020).

A $8^{\circ}$ CRE[7] também argumentou na reunião com as escolas escolhidas em Santa Maria/RS para serem escolas piloto do novo ensino médio, como relata o coordenador pedagógico M.E.:

\begin{abstract}
Você vai dizer: mas que barbaridade! Está exagerando! Mas foi bem assim que a representante da $8^{\circ} \mathrm{CRE}$ falou: "a formação técnica pode qualificar o aluno para uma função no mercado de trabalho, os alunos precisam aprender, por exemplo, a montar móveis, desenvolver competências e habilidades para aprender a fazer coisas úteis para o seu dia a dia". O que é indagado aqui, na perspectiva da escola, é a respeito de qual qualificação crítica que o aluno poderá desenvolver para possuir condições de contribuir socialmente com esse modelo de educação defendido pelo governo estadual (M.E., entrevista, 2020).
\end{abstract}

A escola, portanto, está sendo pressionada dentro de um esforço contrário a uma educação emancipatória e crítica, ou seja:

\begin{abstract}
Nesse sentido, a lógica reproduzida é que o aluno deve saber fazer conta e escrever, embora não tenha desenvolvido o saber interpretar e criar o que ele escreve e possa não possuir uma autonomia crítica a respeito do conteúdo passado em sala de aula, pois, isso não está em discussão agora e muito menos na nova BNCC, que, inclusive, está retirando a obrigatoriedade dos conteúdos de humanas, como os de sociologia e filosofia. O que está em discussão é fazer conta e escrever. É uma lógica contrária a uma educação emancipatória, no sentido de fortalecimento do conteudismo para as competências e habilidades e não da sua superação (E.H., entrevista, 2020).
\end{abstract}

A formação para as competências e habilidades apresenta-se como alternativa ao currículo tradicional (conteudista). No entanto, o que se efetua é uma instrumentalização dos conteúdos incompatíveis, segundo o coordenador pedagógico E.H, com a defesa do acesso ao conhecimento universal construído pela ciência. Destarte, o imediatismo na educação, observável na educação conteudista, continuará no plano da lógica das competências e habilidades. Ou seja, o aluno que ia à 
escola, na demanda conteudista, para aprender conteúdos fragmentados e decorar fórmulas, em uma realidade desigual, onde 52,6\% dos brasileiros com vinte e cinco anos ou mais não concluíram a educação básica, a maior parte, 33,1\%, não terminou o ensino fundamental, aponta a Pesquisa Nacional por Amostra de Domicílios Contínua (PNAD Contínua) (Instituto Brasileiro de Geografia e Estatística [IBGE], 2020), na lógica das competências e habilidades será mantido a fragmentação, pois está sendo implantado uma educação que atenda primordialmente as necessidades do trabalho, sem desenvolvimento de um senso crítico. Assim, observa-se o mantimento da desigualdade ao ser limitado as possibilidades de aprendizado dos alunos da escola pública.

Dessa maneira, se na lógica do conteudismo não era priorizado um modelo de educação para desenvolver o senso crítico e o pensamento autônomo do estudante, na lógica das competências não será diferente. O priorizado na educação será "desenvolver competências e habilidades para o mercado de trabalho, o que aprofundará as desigualdades do acesso à educação para os alunos da escola pública" (M.E., entrevista, 2020). Dessa forma, criam-se novas formas e representações.

Segundo o coordenador pedagógico E.H., a escola L.M. entende que, embora a educação também possa proporcionar o acesso à qualificação profissional, faz-se fundamental que não se distancie da formação do senso crítico. Nas palavras do coordenador pedagógico E.H:

Para nós a educação pode proporcionar o acesso a qualificação profissional, mas de maneira crítica, porque se não o que adianta formar um sujeito que saiba ser explorado, saiba ter salários baixos. Nós precisamos construir sujeitos que tenham críticas a isso. Pelo menos, a nossa ideia enquanto grupo pedagógico é de não manter e fortalecer isso. E essa educação para o trabalho vem na lógica de manter isso, e preparar os estudantes para aceitar esta educação (E.H., entrevista, 2020).

As imposições que são destinadas à escola provocam o descontentamento da categoria. Segundo a diretora N.A., da escola L.M., causam desânimo em muitos professores no empenho de um trabalho em prol de um pensamento crítico e autônomo.

Os professores estão sempre lutando contra imposições que não atendem uma educação emancipatória, a categoria nunca vem trabalhar pensando hoje está tudo certo. Alguns professores estão com o psicológico afetado por causa das reformas, o que faz com que se sintam desmotivados e desanimados (N.A., entrevista, 2020).

A reforma do ensino médio é vista como nociva ao trabalho do professor. Já o Estado argumenta que uma formação voltada para as competências e habilidades oferece oportunidades para o estudante se autorealizar em uma profissão. Em contrapartida, a escola R.A., por exemplo, apresenta as demandas da comunidade escolar como ponto importante para ser trabalhado de forma a contribuir com melhorias na vida do estudante. Para tanto, segundo a vice-diretora A.P., a escola R.A. agrega em seu currículo 
o complexo temático através da pesquisa socioantropológica. Ou seja, a escola procura os temas ligados à realidade do aluno na comunidade, através de trabalho de campo, uma vez ao ano.

Segundo a vice-diretora A.P., a escola R.A. entende que o caminho para a educação está em investimentos e construção de um conhecimento que oportunize aos estudantes ingressarem em cursos superiores. O caminho para educação deve ser onde todos e todas tenham a oportunidade de acessar uma formação universitária. Ou seja, segundo a vice-diretora A.P.:

O caminho para educação é ter acesso a cursos superiores, todos terem acesso a uma formação universitária. Pois estes cursos técnicos, alunos que trabalham como jovem aprendiz, e parcerias com as entidades, servem para um auxílio de custo para o aluno continuar estudando. Aqui a escola trabalha com uma comunidade bem pobre e entende que se o aluno participa de algum desses programas é bom para ele se manter melhor e para continuar estudando. Mas eu não acredito que seja pensando na educação. As empresas fazem isso visando, para além da mão de obra barata no presente, a formação de trabalhadores para seus cargos e demandas do mercado (A.P., entrevista, 2020).

Entretanto, a escola ainda toma como eixo formar alunos autônomos. Na cultura da escola está inscrita a preocupação por uma educação que possibilite ao aluno alcançar autonomia. No entanto, o coordenador pedagógico M.E., da escola R.A., ressalta que a escola vigente se distancia do modelo de educação defendido pela categoria:

É uma lógica que está longe de ser uma educação que a gente quer, que é a autonomia do aluno. É uma lógica do ponto de vista neoliberal, um modelo de Estado mínimo, de menor investimento na educação pública. Nós estamos dizendo o seguinte: as escolas privadas continuarão com todas as disciplinas, já os alunos das escolas públicas são obrigados a seguir a nova matriz curricular do novo ensino médio. A escola pública terá um prejuízo. É uma lógica neoliberal, lógica de sucateamento da escola pública. Falam da escola sem partido, que nós doutrinamos os alunos, mas na verdade o que está se propondo é uma escola dogmática, uma escola que doutrina, porque é uma escola que não faz o aluno crítico. $\mathrm{O}$ aluno crítico não é aquele que segue o que o professor pensa, mas sim é o aluno que tem condições de olhar para o que o professor diz e para o que os outros dizem e, então, formar a opinião dele. É o aluno que tem autonomia de criar e de pensar. E o que estamos fazendo hoje é podar essa autonomia. Então, a escola dogmática, sem o pensamento crítico, não é a que estamos lutando e pautando, mas sim é essa que está chegando agora. É essa que vem aí (M.E., entrevista, 2020).

\section{AMPlação do TRABAlho dOCENTE E A RELAÇÃo COM A CRISE dAS FINANÇAS ESTADUAIS}

Segundo a diretora N.A., da escola L.M., "a escola está saturada pelas exigências das reformas. Quando termina de se adaptar a uma, vem outra e mais outra. Nesse sentido, o professor sente que seu trabalho está sendo intensificado por demandas em desacordo com a cultura da escola" (N.A., entrevista, 2020). Na escola, o seu trabalho assume, junto com a equipe escolar, a responsabilidade por todas as atividades realizadas. A respeito de atividades externas, além de trazerem certificação e verbas para a instituição escolar, geram cobranças em cima de cada membro da equipe na busca pelos resultados positivos nessas atividades. A exemplo, sublinha-se a participação da escola na Olimpíada 
Brasileira de Matemática (OBM), concursos literários e na Olímpiada Brasileira de Gastronomia (OAG) (E.H., entrevista, 2020).

O professor R.J. relatou ser responsável por todas as turmas de primeiros e segundos anos do ensino médio da escola M.F., o que soma vinte e sete turmas. Como a disciplina que ministra, sociologia, só tem uma vez na semana, é preciso que assuma o número de turmas citadas para cumprir a sua carga horária, o que aumenta, consequentemente, o número de trabalhos e provas para corrigir, as preocupações com a avaliação de cada aluno, a jornada, a carga horária de trabalho e a cobrança por resultados e produtividade. $\mathrm{O}$ aumento de trabalho do professor opera como forma de fazer com que os professores forneçam conhecimento escolar básico a um maior contingente de alunos em um mesmo espaço de tempo. Assim, barateia-se o custo do serviço educacional.

Desse modo, como aponta o relato acima, o professor tem o seu trabalho ampliado para além da carga horária formal e está submetido a cobrança por produtividade sem investimentos no seu trabalho. Em relação as condições de trabalho o coordenador pedagógico E.H., da escola L.M., destaca no relato abaixo a desvalorização salarial e falta de incentivos, acompanhada de cobranças no que tange o desempenho do professor.

Essa lógica desenha a ideia de que o professor é o inimigo da escola e do estado porque faz greves e paralizações criticando as medidas do estado para o seu trabalho. Essa lógica, na verdade, é uma inversão, mas estão vendendo isso para a sociedade, nós somos os inimigos da escola. Somos cobrados sempre mais, temos que trabalhar mais, mas não há valorização do salário e nem incentivos. Sentimos só aumento de trabalho e cobranças cada vez maiores e mais frequentes. (E.H, entrevista, 2020).

Desse modo, foi observada uma intensificação no trabalho do professor, com o acréscimo de trabalho compensando a falta de investimento em educação. Segundo o coordenador pedagógico E.H., falta dinheiro na escola, mas isso não significa que falte dinheiro no estado. O sindicato dos professores do RS, denominado Centro dos Professores do Estado do Rio Grande do Sul (CPERS) (2018) informa que, segundo o governo Sartori (MDB), “os salários da categoria não são reajustados porque não há dinheiro" (CPERS, 2018). No entanto, o CPERS argumenta que quando aumentou impostos, o governo passou a possuir mais fundos: a arrecadação cresceu em dez bilhões de reais de 2015 para 2017 e superou as despesas. Ou seja, segundo o coordenador pedagógico E.H e o sindicato da categoria, há financiamento para a educação, porém sofre com a administração do governo do estado.

A década de 1990, com o acentuamento do projeto neoliberal, concretiza a emergência de um projeto de Estado mínimo, disputando a hegemonia política- cultural com o projeto democrático que surge com a nova Constituição Federal de 1988, que consagrou o princípio de participação da sociedade civil (Dagnino, 2004). Com a nova Constituição Federal de 1988, as forças envolvidas em sua 
constituição compartilham, conforme (Dagnino, 2004), um projeto democratizante e participativo, expandindo a cidadania e aprofundando a democracia. Tal projeto, segundo Dagnino (2004), emergiu da luta de setores da sociedade civil contra o regime militar.

A democracia formal foi reestabelecida, com eleições livres e a reorganização partidária, concedeu a possibilidade de que o projeto democrático pudesse ser levado para o âmbito do poder do Estado, fazendo dos anos noventa cenário de numerosos exemplos desse trânsito da sociedade civil para o Estado. Assim, contando com a ampla participação popular, a nova Constituição Federal de 1988 fica conhecida como a Constituição mais democrática da história do Brasil. Conforme Dagnino (2004), durante esse mesmo período, o confronto e o antagonismo que tinham marcado o Estado e a sociedade civil nas décadas pretéritas deram lugar a uma aposta na possibilidade da sua ação conjunta para o aprofundamento democrático. A participação da sociedade se tornou central como característica distintiva desse projeto, subjacente ao próprio esforço de criação de espaços públicos onde o poder do Estado pudesse ser compartilhado com a sociedade (Dagnino, 2004).

De outro lado, com a eleição do presidente da república Fernando Collor de Mello em 1989 e como parte da estratégia do Estado para a implementação do ajuste neoliberal, segundo Dagnino (2004), há a emergência de um projeto de Estado mínimo que se isenta progressivamente de seu papel de garantidor de direitos, através do encolhimento de responsabilidades sociais e transferência das mesmas para a sociedade civil. Este projeto constitui o núcleo duro do bem conhecido processo global de adequação das sociedades ao modelo neoliberal produzido pelo Consenso de Washington (Dagnino, 2004).

De acordo com Frigotto (2007, p. 1137): “com o governo Collor, inicia-se a cega adesão à doutrina neoliberal. Os debates políticos e econômicos são substituídos pelo discurso técnico gerencial e pelo ideário do ajuste, descentralização, flexibilização e privatização". Isso continuou nos oito anos do governo do Fernando Henrique Cardoso (FHC) (1995-2002). Mas ainda antes do FHC, com Collor no poder, “deflagrou-se o processo de ajuste da economia brasileira às exigências da reestruturação global da economia" (Evangelista, Moraes, \& Shiroma, 2004, p. 46).

Mesmo com o impeachment de Collor, sua saída do poder em 1992, o projeto neoliberal vai se consolidando, dado que tem ajuda e é pressionado por agências internacionais que monitoram os empréstimos financeiros no país. As principais agências são, segundo Arelaro (2000), o Banco Mundial e o Fundo Monetário Internacional (FMI).

Tendo em vista o projeto neoliberal de sociedade, a conclusão do CPERS é que a crise e a falta de dinheiro no estado do RS fazem parte de um projeto de governo. Em 2018, com um déficit estimado em 6.9 bilhões em reais, calcula-se que o RS deixou de arrecadar 7.8 bilhões de reais com sonegação de impostos por ano e 9 bilhões de reais em isenções fiscais para empresas (CPERS, 2018). 
Nesse ínterim, a gestão escolar deverá efetivar as metas e resultados da educação com os recursos disponíveis. Esses devem ser buscados nos bons resultados, em avaliações, em atividades e projetos. A gestão escolar, nessas circunstâncias, de descentralização dos gastos administrativos sobre a figura do estado, arca com a bandeira da utilização eficiente dos recursos e melhoria na produtividade dos serviços; sem que isso represente aumento de gastos.

\section{CONSIDERAÇÕES FINAIS}

As ações que caracterizam um "quase-mercado" na escola são justificadas pela falta de materiais que há nas escolas e que podem ser oferecidos pelas empresas. Por essa via, a instituição privada consegue conquistar a adesão da instituição escolar aos seus produtos, sejam esses, por exemplo, uma pintura, um serviço de reforma ou uma instalação de rede wi-fi. Com a publicidade, essas empresas ganham novos consumidores e investem em uma imagem positiva para si.

Observa-se que o estado, no período do governo Sartori (MDB), implantou, através do projeto "Escola Melhor: sociedade melhor”, uma parceria entre escolas e pessoas jurídicas ou físicas, em troca, além de ser reduzida a responsabilidade do governo estadual com a manutenção das instituições escolares, as empresas puderam realizar publicidade dentro das escolas.

Em relação ao Sistema $S$, tratando dos jovens estudantes, está oferecendo alternativas estimulantes como uma capacitação profissional ou estágio remunerado. São oportunidades que, em certa medida, mostram possibilidades de autorrealização e incentivos para alguns alunos estudarem.

Já no projeto “Jovem RS Conectado no Futuro", é possível identificar um plano que tem por princípio o maior aproveitamento do próprio espaço escolar para ser passado aos alunos uma formação dentro da cultura do empreendedorismo. Mesmo assim as parcerias continuam existindo, como as existentes com o Sistema S.

Este artigo identificou uma resistência da cultura da escola à introdução de mudanças na educação baseadas em lógicas mercantis. Os interlocutores ao demonstrarem práticas de resistências, como a recusa do convite para testarem o novo ensino médio na escola, mostram-se descontentes com um modelo de educação de base tecnicista. E, trabalhando com projetos, como, por exemplo, o Show de Talentos, estão no exercício da sua atividade aliviando as tensões de uma educação focada numa formação para o trabalho.

A educação defendida pelos docentes interlocutores dessa pesquisa é antagônica a uma formação direcionada exclusivamente para o mercado de trabalho. A resistência associada à autonomia escolar tem a ver com a capacidade da instituição de preparar o aluno para a vida social como um todo e não apenas para o mercado de trabalho. Nesse caso, preservar dos riscos que ações do tipo "quasemercado", somado ao empreendedorismo na escola, representam à natureza da escola pública. 
Também se percebeu que há uma intensificação do trabalho do professor - sem acréscimo correspondente nos salários - em decorrência de um escasso investimento em educação. Assim, o estado que vê nas parcerias público-privadas um meio de enxugar gastos, igualmente produz a intensificação do trabalho docente com o mesmo propósito.

Estas questões mais estritamente relacionadas com a precariedade das condições de trabalho ganharão enfoque em pesquisas posteriores, assim como uma abordagem envolvendo o processo de reconfiguração das políticas educativas a uma escala transnacional e as suas repercussões na atividade docente.

Uma abordagem reflexiva sobre a história das políticas educativas no Brasil em razão dos limites do artigo também ficará para pesquisas posteriores. Bem como uma descrição detalhada de onde se observa ao nível dessas políticas educativas a concretização da agenda neoliberal.

Em razão dos limites do artigo, não foi possível explorar todos os temas pertinentes. Dentre os já citados, também está a relação entre novas demandas produtivas e a reforma do ensino médio que está para ser implantado no ano de 2021. As questões que envolvem essas articulações, portanto, serão exploradas futuramente. 


\section{REFERENCIAS}

[1] O termo Sistema S é como se define o conjunto de organizações das entidades corporativas, alguns exemplos são: Serviço Nacional de Aprendizagem Industrial (SENAI), Serviço Social do Comércio (SESC) e Serviço Social da Indústria (SESI). As empresas pagam contribuições às instituições do Sistema S com base em alíquotas (Senado Federal, 2020).

[2] O PPP (Projeto Político Pedagógico), documento que contempla a perspectiva educacional da instituição, é resultado da reflexão e da avaliação de todos envolvidos com a educação da escola: equipe diretiva, equipe pedagógica, professores, alunos, pais, membros do CPM e membros do Conselho Escolar, tendo em vista o compromisso de todos com a educação. Encontra-se disponível na referida escola.

[3] Os interlocutores da pesquisa foram citados pelas iniciais dos nomes. E as informações foram obtidas através de entrevista com membros da equipe diretiva e professores das escolas públicas estaduais da cidade de Santa Maris/RS, entre os anos de 2018 e 2020.

[4] As escolas do campo investigado também foram citadas pelas iniciais dos nomes.

[5] O projeto "Jovem RS Conectado no Futuro" contou, para o seu desenvolvimento, com parceria do Sebrae-RS, da Rede Gaúcha de Ambientes de Inovação, do Instituto Federal do Rio Grande do Sul, das Secretarias da Inovação, Ciência e Tecnologia da Ciência e do trabalho e assistência social, da Universidade de Passo Fundo, da Universidade Federal de Santa Maria, da Universidade Federal do Pampa, da Unijuí, da Universidade Federal de Pelotas e da Elefante Letrado Plataforma de Leitura (Scarton, 2019).

[6] Os Itinerários Formativos são o conjunto de disciplinas, projetos, oficinas, núcleos de estudo, entre outras situações de trabalho que os estudantes poderão escolher no novo ensino médio. Eles podem se aprofundar em uma área do conhecimento e da formação técnica e profissional (FTP) ou mesmo nos conhecimentos de duas ou mais áreas e da FTP (Ministério da Educação, 2020).

[7] O ex-ministro da educação, Abraham Weintraub, em evento em São Paulo, no ano de 2019, defendeu a ampliação do ensino técnico no Brasil. Sua fala assemelha-se aos argumentos da $8^{\text {a }}$ CRE a respeito da conexão do novo ensino médio com o mercado de trabalho. Ou seja, Abraham Weintraub defendeu que a escola tem que ensinar um ofício. Relatou que "está cheio de doutor sem emprego, mas é difícil ter um bom encanador passando fome ou na fila do bolsa família. É difícil um eletricista, um técnico bom, que não consegue se virar". Abraham Weintraub ainda acrescentou que a meta até o final do governo federal é aumentar em $80 \%$ o número de alunos no ensino técnico (O Antagonista, 2019). 